\title{
Del catolicismo al cristianismo. Reflexión sobre el itinerario religioso de José L. L. Aranguren
}

\author{
MANUEL FRAIJÓ
}

\section{Introducción}

El título de estas páginas casi exige comenzar con una puntualización: catolicismo y cristianismo no son, obviamente, denominaciones contrapuestas. El catolicismo forma parte del rico entramado de confesiones religiosas a las que ha dado lugar el cristianismo. El cristianismo cs, por así decir, la denominación de origen. $Y$, durante siglos, el adjetivo «católico», entendido como "universal», convivió pacíficamente con el cristianismo y se convirtió en una característica irrenunciable de la Iglesia.

$\mathrm{Ni}$ siquiera las Iglesias surgidas de la Reforma protestante renunciaron a la catolicidad. Melanchthon escribió: «Todos nosotros tenemos que ser católicos». Los protestantes consideraron que la catolicidad era una herencia a salvar. Su elevado rango teológico la mantenía al margen de las diferencias doctrinales y políticas surgidas en el seno de las confesiones cristianas. Las Iglesias a las que dio lugar la Reforma del siglo xvi identifican la catolicidad con la recta predicación de la palabra y la adecuada administración de los sacramentos. La catolicidad las vincula directamente con los orígenes cristianos. Es ella la encargada de testimoniar que las nuevas confesiones no son hijas de una especie de segunda hora. También ellas son apostólicas y se remontan a la hora inicial en la que todo surgió ${ }^{1}$.

Sin embargo, las luchas entre la Reforma y la Contrarreforma dieron lugar, como es sabido, a muchas apropiaciones indebidas. Una de ellas, y no precisamente la menos importante, fue llevada a cabo por la Iglesia «de siempre», por la que se consideraba única depositaria de la «tradición». Esta Iglesia logró que lo católico fuese identificado con lo romano. A partir de entonces, ambas confesiones cristianas, el catolicismo y el protestantismo, han buscado su especificidad desde la mutua confrontación. Por lo general, el protestantismo ha reclamado para sí la dimensión profética del cristianismo y el catolicismo la dimensión sacramental. Pcro Aranguren nos hará ver que el asunto es mucho más complejo.

Y será, también, Aranguren quien nos explique cómo entendió su paso del catolicismo al cristianismo. En esta introducción sólo hemos querido indicar que pasar del catolicismo al cristianismo no es como cambiar de nacionalidad,

Cf. LI. Duch, «Catolicismo», en C. Floristán y J. J. Tamayo (eds.), Conceptos fundamentales del cristianismo, Madrid, Trotta, 1993, pp. 163-172. 
de familia o de idioma. Es más: Aranguren siempre estuvo en el cristianismo y nunca dejó de estar por completo en el catolicismo. Es un problema de acentos, de prevalencias, de matices. Pero un problema importante.

Deseo concluir esta introducción con otra advertencia, esta vez de tipo personal. Percibo que, para mí, es aún pronto para escribir sobre Aranguren. De hecho, he ido retrasando, sin causa justificada, la hora de ponerme a redactar estas líneas. En algún sentido, ha sido un retraso en defensa propia. Escribir sobre Aranguren significa hacerme consciente de que él ya no está, de que estas páginas formarán parte de un homenaje póstumo. Es como volver al cementerio de Ávila, la ciudad que él evocó como «lejana, entre pétrea y mística», la ciudad a la que quiso «ser llevado a reposar» 2 .

Decía A. Machado, sobre quien Aranguren escribió páginas muy bellas, que el principal talante ético es el de la «bondad». Tal vez resida ahí cl secreto de Aranguren. Fue su bondad, sencillez y cercanía lo que avaló su magisterio ético y espiritual. Para muchos de nosotros, sin Aranguren nada volverá a ser igual. Siempre nos faltarán sus palabras, sus prolongados silencios, su cordialidad, su complicidad con todo lo noble y humano. Tal vez por eso, ni aun viéndole en agonía, nos llegábamos a creer que fuera a morir.

Cuando falleció su maestro y amigo, E. D'Ors, Aranguren escribió que D’Ors había muerto «lo menos solemnemente posible». Y consideraba simbólico que su última glosa tratase de la «elegancia» ${ }^{3}$. Tampoco la muerte de Aranguren fue solemne. Y también su vida fue una lección de elegancia.

Hacia el final de su artículo sobre la muerte de D'Ors, Aranguren escribió: «El espíritu no muere, el diálogo prosigue, la palabra no puede extinguirse» ${ }^{4}$. Aferrándome a esta voluntad de diálogo, escribo hoy sobre Aranguren. Los organizadores de este homenaje, pensando sin duda en mi dedicación a los temas relacionados con la religión, me piden que evoque lo que tantas veces se ha llamado «la sostenida dimensión religiosa del pensamiento de Aranguren». Deseo hacerlo de forma distendida y sin pretensión de exhaustividad. Me interesaré más por el bosque que por los árboles. Además; la extensa producción de Aranguren sobre el tema no deja otra alternativa. Son muchos los cientos de páginas que dedicó al estudio de la religión ${ }^{5}$. Alguna vez escribió que se había dedicado «por igual» a la ética y a la religión.

Comenzaré por el final, es decir, por la evocación que de la religiosidad de Aranguren hicieron algunos discípulos y amigos en los días que siguieron a su muerte. Se tratará de una información muy breve. Estoy casi seguro de que él habría aprobado cste procedimiento.

${ }^{2}$ J. L. L. Aranguren, Avila de Sunta Teresa de Jesús y de San Jaun de la Cruz, Barcelona, Planeta, 1993, p. 15.

${ }^{3}$ J. L. L. Aranguren, La filosofia de Eugenio d'Ors, en Obras Completas, vol. 1, Madrid, Trotta, 1994, p. 97.

Ibid., p. 98.

s Cf. la excelente información de F. Blázquez, José Luis L. Aranguren. Medio siglo de lo historia de España, Madrid, Ethos, 1994, pp. 75-132 y 246-259. 


\section{Las voces de los mâs cercanos}

Fue la de Aranguren una religiosidad «en modo alguno apabullante». Así se expresaba, al día siguiente de la muerte de su maestro, Javier Muguerza ${ }^{6}$. Reconoce que era «profundamente religioso»; pero, al tratarse de una religiosidad abierta, crítica, e incluso hetcrodoxa, la religiosidad de Aranguren «abría la puerta a un interés en reciprocidad respetuoso». Una religiosidad que hacía posible el diálogo entre creyentes e increyentes. Un diálogo que actualizaba lo que Aranguren llamaba «la dialéctica del espiritu humano». Tal dialéctica se articula en una especie de drama con tres protagonistas: el metafísico, que formula las grandes preguntas; el religioso, que se afana en la respuesta; y el escéptico, que rechaza las respuestas y, a veces, el sentido mismo de las preguntas. Muguerza reconoce que el pensamiento de Aranguren le ha obligado a «matizar» personalmente la postura escéptica, la única que cree poder atribuirse en este reparto de papeles.

Tendremos que retornar al diálogo sobre la religión mantenido entre Muguerza y Aranguren. El discípulo supo «arrancar» al maestro sus mejores pronunciamientos sobre el hecho religioso. Algo nada fácil. El Aranguren de los últimos años se mostraba reacio a hurgar en el tema.

En este momento sólo nos interesa destacar que la religiosidad de Aranguren, como la de tantas otras personas, caminó del brazo del tiempo y de la historia. Muguerza evoca el estadio final, el de la madurez plena. Es la hora en la que Aranguren considera que lo más «interesante» de la religión no son las respuestas que ofrece, sino las grandes preguntas que suscita; es cl momento en el que, a pesar de sentirse profundamente cristiano, experimenta la dificultad de trazar fronteras nítidas entre la creencia y la increencia; son los días de su predilección por otro grande del cristianismo, por el K. Barth que advertía en su interior la simultánea presencia de la fe y la incredulidad. Pero, antes de conquistar esta especie de cristianismo inquieto, abierto a la duda y a la pregunta, Aranguren conoció y vivió otras figuras del cristianismo más conformistas y acríticas, sobre las que posteriormente volveremos.

También Pedro Cerezo, otro destacado discípulo de la primera hora, se arrima al Aranguren final, al que se mantenia «en la pregunta como su modo genuino de ser religioso" ${ }^{7}$. Considera al maestro «un hombre rotundamente religioso» que vivió el lado positivo de la religión, su vertiente amable y consoladora, pero que también apuró «la experiencia de la noche oscura», la cara negativa de la soledad y la desolación. Hombre de talante «bifronte» - prosigue Cerezo-, Aranguren estaba en el mundo como un ser perplejo, desorientado

'J. Muguerza, «Los puntos suspensivos», en $A B C, 18$ de abril de 1996.

Cf. el breve resumen de la intervención de $\mathrm{P}$. Cerezo en el homenaje que el $\mathrm{XX}$ Foro sobre el Hecho Religioso dedicó a Aranguren el 27 de septiembre de 1996. Está publicado en Memoria académica $1995-96$ del Instituto Fe y Secularidad, pp. 180 y ss. 
a veces, y probablemente con fuertes crisis de fe; pero, al tiempo, le acompañaba una tibia esperanza, una certidumbre oscura de que «Dios no se ha podido quedar atrás». Por eso, más que transmitir certezas, Aranguren inspiraba una confianza casi paternal.

Cerezo descubre la rcligiosidad de su maestro en una doble aceptación: la del misterio del mundo, y la de la coherencia de los valores respecto a un valor incondicional. $Y$ algo muy crucial: la vocación de Aranguren estuvo siempre íntimamente vinculada a la libertad. Libertad «de» servidumbres innecesarias, y libertad «para» actuar lúcidamente en el mundo. Una libertad de raíz profundamente cristiana que le condujo a levantar su voz contra formas de religión demasiado eclesiásticas que sofocan la autonomía moral. Defendió la apertura de la ética a la religión, pero se negó a convertir la religión en un recetario moral. Cerezo termina evocando «el alargamiento de la ética en la escatología». Algo casi inevitable en el homo religiosus que fue Aranguren.

Finalmente, José Gómez Caffarena, tán cercano a Aranguren durante muchos años, nos recuerda que éste nunca renunció a su condición de cristiano. Es verdad que, durante los últimos treinta años, la dimensión religiosa perdió «la centralidad» que tuvo en las primeras etapas de la vida intelectual de Aranguren. Pero Caffarena cree, con razón, que fue el mismo espíritu cristiano de los inicios quien le movió a «rectificar» de forma coherente y matizada, sin traicionarse a sí mismo. El principal ámbito de rectificación se sitúa en la eclesiología. De la inicial e incondicional adhesión a la Iglesia, incluido su magisterio jerárquico, Aranguren pasó a distinguir entre la «Iglesia eclesial» y la «Iglesia jerárquica». La primera siguió contando con su afecto y adhesión; la segunda recibió de él justificados reproches. La encontraba autoritaria, dogmatista y alejada de los problemas reales de la sociedad. Frente a ella, como frente a cualquier instancia autoritaria, Aranguren se mostró heterodoxo ${ }^{8}$.

Hemos acudido a tres personas muy centrales en la vida y en el corazón de Aranguren para que nos allanen el camino hacia su dimensión religiosa. Se trata de tres intérpretes que gozan de la autoridad que les otorga su conocimiento de la persona y la obra del maestro desaparecido. Ellos evocan la madurez última, el resultado final. Nosotros ofreceremos unas cuantas pinceladas sobre los estadios previos, sobre las fatigas de un itinerario religioso forjado en tierra de penumbra. No otra cosa era la España que Aranguren intentó adecentar. Penumbra teológica, páramo cultural, férrea dictadura política y asfixiante miseria social. En suma: mucha religión, mucha hambre, pocos libros y ninguna libertad.

${ }^{8}$ J. Gómez Caffarena, «In memoriam: José Luis López Aranguren», en Razón y $F e_{*} 233$ (1996), pp. 651-658. 


\section{A solas consigo mismo}

Por ahí empezó todo. Pascal dejó dicho que la tragedia del hombre moderno se condensaría bajo un dramático rótulo: incapaz de soledad. Nadie aguantaría una hora en su habitación. No fue éste, ciertamente, el caso de Aranguren. Por supuesto, como todo ser humano, terminó solo, o en esa imperfecta soledad que únicamente turba la presencia de la muerte, el último «tú» a quien hacemos sitio.

Pero la soledad del «solitario solidario» que fue Aranguren comenzó mucho antes. Ni siquiera conoció el barullo de la escuela de Ávila. Tuvo un profesor particular. Y muy pronto, a los cuatro años, le visitó la soledad fundamental, la de la pérdida de su madre. Se trató de una soledad que ya nunca le abandonaría. Los que tuvimos la suerte de compartir espacios de su vida lo sabíamos. Él mismo se confesaba tímido y «distante».

También su religiosidad comenzó siendo $-\mathrm{y}$ lo fue siempre - intimista y privada. La formación jesuítica, en esto algo protestante, enfrenta severamente al individuo consigo mismo. El hombre ignaciano no se pierde nunca de vista a sí mismo. Rigurosos exámenes de conciencia lo mantienen siempre alerta.

Aranguren asimiló esta espiritualidad. Llegó a considerarse «medio jesuita». $\mathrm{Y}$ jesuitas fueron algunos de los hombres a los que quiso y admiró. A la cabeza de todos ellos habría que situar al P. R. Ceñal, cuyo «destierro» a Chile Aranguren tanto lamentó. Le siguen Ios tres «Josés»: Llanos, Díez-Alegría y Gómez Caffarena. En las intervenciones públicas de los últimos años, Aranguren recordaba con afecto los años que pasó en el colegio de Nuestra Señora del Recuerdo, en Madrid.

La espiritualidad de los jesuitas, el austero paisaje de su Ávila natal, su natural predisposición a la soledad, y una circunstancia nacional de reducidas ofertas externas ensimismaron al Aranguren joven. Su época «frivola» -así la calificaba él- no duró mucho. Muy pronto, la agitación de la República y el desastre de la guerra le impidieron "fardar de coche nuevo".

Ni siquiera el paso por su admirada Facultad de Filosofia rompió su aislamiento: «... mi timidez me impidió dar los pasos necesarios para ligarme personalmente a alguno de los admirados maestros»". Se refiere a García Morente, a quien sucedería en la cátedra de Ética, a Ortega y, sobre todo, a Zubiri, a quien confiesa deber lo mejor de su Ética.

La guerra civil reforzó su ensimismamiento. Confiesa que, durante ella, sintió un «fervor religioso» que nunca más «he vuelto a sentir con tal intensidad» ${ }^{10}$. Muchos años después, en 1969, evoca aquel intimismo religioso-existencial «como un refugio, el primero construido por mí mismo, de la realidad

\footnotetext{
9 J. L. L. Aranguren, Memorias y esperanzas españolas, Madrid, Taurus, 1969, p. 38.

${ }^{10}$ Ibid., p. 39.
} 
exterior, del entorno bélico» ". Pero continúa pensando que se trató de una «religiosidad muy intensa» de cuya «autenticidad» no duda. La guerra civil significó para él «extrañamiento de un entorno en el que yo no tenía nada que hacer». De ahí que se tornara en un tiempo religioso, en «una especie de retiro espiritual, que se prolongaría en la inmediata postguerra hasta finales del $41{ }^{12}$.

Es significativo que su primer ensayo, anterior al dedicado a La filosofia de Eugenio D'Ors, se titulase «San Juan de la Cruz, maestro de la vida espiritual». Lo presentó, en 1945, a un certamen organizado con motivo de la celebración del IV Centenario del gran místico español. El premio fue declarado desierto, pero, años más tarde, el trabajo de Aranguren sirvió de introducción a las Obras Completas de San Juan de la Cruz ${ }^{13}$. No se trató de un ensayo ocasional. En 1971, durante su docencia en la Universidad de Santa Bárbara, en California, dictó un curso sobre el místico abulense.

San Juan de la Cruz, Santa Teresa, Kierkegaard, Dostoiewski, R. Otto y la obra de $\mathrm{M}$. Scheler, pasajeramente convertido al catolicismo, fueron algunas de las lecturas de aquellos años. Fueron años de intensa vida espiritual e intelectual. Él mismo dirá que, «aunque de lejos», siguió el ejemplo de Descartes y dedicó «las largas horas vacías de la guerra» a la meditación religiosa y filosófica. Escribió, incluso, «bastantes trabajos», que califica de «muy pretenciosos» y que destruyó ${ }^{14}$.

Lo que no destruyó, por suerte para todos, fue Catolicismo y protestantismo como formas de existencia. Es, sin duda, su obra más lograda. La comenzó a escribir en 1944. Él mismo informa de que la empezó antes de concluir La filosofia de Eugenio D'Ors. Sería publicada por Revista de Occidente en 1952. Nos ocuparemos de ella en el apartado siguiente.

En este momento sólo deseo resaltar que, posiblemente, estos oscuros años de «vida oculta», de alejamiento del mundanal ruido, forjaron al Aranguren posterior. Fuc aquí, cn contacto con la meditación y la reflexión, con la filosofía y la teología, con la mística y la poesía, donde nació y se desarrolló su experiencia religiosa. Hubo, como veremos, evoluciones posteriores; pero el fondo administrado nació en estos años de silencio, recogimiento y fervor religioso. Fue éste su auténtico catecumenado, su Damasco decisivo. Lo que vino después tuvo siempre una referencia obligada: su encuentro con Dios antes, durante y en los años que siguieron a la guerra civil. Por lo demás, así suele ocurrir: la experiencia religiosa de los creyentes tiene - necesita - momentos fuertes, fechas clave, espacios para el recuerdo. Es la hora de la intensidad. Y, como casi nadie puede instalarse en la intensidad, llegan después los años y los

"Ibid., p. 40.

"2 E. López-Aranguren, J. Muguerza y J. M. Valverde (eds.), Retrato de José Luis L. Aranguren, Madrid, Círculo de Lectores, 1993, p. 73.

"Obras que fueron publicadas por la editorial Vergara, Barcelona, 1965.

14 J. L. L. Aranguren, Memorias y esperanzas españolas, p. 51. 
días en los que el hombre religioso, perdido el ardor primero, administra la herencia de antaño y recuerda los momentos fundantes que vivió. No quiero decir que no sea posible el progreso; pero se realiza dentro del humus inicial, tal vez a la sombra de una intensidad lejana. A veces, pero creo que no fue el caso de Aranguren, sólo queda una tenue melancolía.

\section{La llamada del exterior}

El ensayo sobre Eugenio D'Ors fue bastante decisivo en la vida de Aranguren. Su nombre comenzó a ser conocido. $Y$ algo muy importante: al trasladarse E. D'Ors a Madrid, Aranguren comenzó a asistir a sus tertulias. Desde entonces - escribe- «mi vida cambió externamente mucho; de solitario me convertí, ante la afectuosa insistencia del querido maestro, en hombre casi social, mucho más de lo que era y es mi inclinación» ${ }^{15}$.

Fue allí donde conoció a Luis Felipe Vivanco y, a través de él, a Luis Rosales y Leopoldo Panero. Unos le fueron llevando a otros y, en poco tiempo, se vio inmerso en los círculos literarios e intelectuales del país. En concreto se incorporó a la revista Esconial. Allí coincidió con «católicos que tendían también hacia un intimismo existencial en grados diversos». Mucho más tarde recordará que el grupo, al que también pertenecían Pedro Laín y José $\mathrm{M}$. Valverde, se retraía «a una vida religioso-trascendente, vida unamuniana, pero aserenada, a la búsqueda y encuentro de Dios» ${ }^{16}$.

Los nuevos amigos no merman, pues, su religiosidad, sino que mitigan su soledad. $Y$ algo muy importante: a partir de ahora, Aranguren será un pensador con repercusión. Ya no se dedicará a emborronar folios que, a continuación, destruye. Ahora, lo escrito permanece y ve la luz pública. Y su gran tema sigue siendo el hecho religioso en sus múltiples articulaciones y manifestaciones. La ética y los asuntos sociopolíticos vendrán más tarde.

Al asomarse al mundo exterior, Aranguren ha comenzado su «acción católica intelectual», o lo que él llamaba su «acción católica con minúscula». Una acción - un compromiso- que se desplegó en diversos frentes. Los iremos enumerando. Pero es de rigor empezar por el que consideramos más decisivo: la publicación de Catolicismo y protestantismo como formas de existencia.

$\mathrm{Si}$ algo nocesitaba el catolicismo español de aquellos años era una zambullida en la teoría. Había mucha práctica católica y poca reflexión. Y se vivía como si no hubiese tenido Iugar la Reforma protestante. En este sentido, el libro de Aranguren fue un novum absoluto. El hecho de que, en aquel páramo teológico, un investigador privado, de indudable trayectoria católica, recorriese diariamente la corta distancia que separa las calles Velázquez y Pablo Aranda para leer a Lutero y Calvino en la residencia donde vivía lo más granado

\footnotetext{
${ }^{15} \mathrm{Ibid}, \mathrm{p} .58$.

Thid., p. 65.
} 
de la intelectualidad jesuítica del momento debe ser considerado como un acontecimiento bastante excepcional.

La cosa sube de tono si se tiene en cuenta que en aquella casa, denominada «casa de escritores», sólo se escribía sobre el protestantismo para refutarlo. No puede, pues, extrañar que algunas de las más ácidas reacciones contra el libro de Aranguren procediesen de algunas plumas asentadas en Pablo Aranda y que tenían como órgano de expresión la prestigiosa revista Razón y Fe. Más tarde volveremos sobre ellas ${ }^{17}$.

Pero retornemos al libro de Aranguren. Él mismo se encarga, en el prólogo a la edición de 1980, de situar el término a quo de la obra: «... un catolicismo orsiano-guardiniano, clásico o clasicista, cultual-cultural, benedictinista de María Laach». Y el término ad quem: «un cristianismo existencial» ${ }^{18}$. Obsérvese que Aranguren habla ya aquí de un tránsito del catolicismo al cristianismo. $\mathrm{Y}$, en el mismo lugar, apostilla que lo que en otro tiempo llamaba «acción católica con minúscula» lo llamaría hoy «acción cristiana (o no lo llamaría de ninguna manera) w. Llamo la atención sobre este dato para ir justificando el título que he dado a esta colaboración: Del catolicismo al cristianismo. Más tarde aportaré más indicios. Con todo, deseo dejar constancia ya aquí de que no se trató de un tránsito brusco. Aranguren no se acostó una noche católico y se levantó cristiano. Tales, llamémoslas «conversiones», llevan, en personas como Aranguren, la impronta de la lenta y pausada meditación.

Ahora debemos insistir en que esta obra de Aranguren es, probablemente, el primer intento sistemático que se hace en nuestro país por comprender el protestantismo. El otro intento, el de Unamuno, fue más entrecortado y visceral, más subjetivo y agitado. Aranguren procede con objetividad. Su discurso es sereno, metódico, progresivo, «científico». Pero, al mismo tiempo, no cuenta una batalla que le deje indiferente. Su aproximación a Lutero, Calvino, Pascal, Kierkegaard, Barth y la teología dialéctica, R. Otto, el anglicanismo, la Compañía de Jesús y sus Ejercicios espirituales, la Contrarreforma, el jansenismo y el talante religioso de Miguel de Unamuno es cercana y cordial. Hay ánimo de comprensión y no voluntad de refutación. Aranguren se autoimplica en su investigación.

Hay que decirlo: si Aranguren hubiese sido un teólogo profesional, no hubiese podido escribir esta obra. Este libro, su mejor libro, le salió así porque se acercó al tema sin prejuicios dogmáticos ni apologéticos. Por aquellas fechas, él era católico de rigurosa observancia; pero su estricta confesionalidad no mermó su clarividencia. Se tiene la impresión de que se acerca a los textos con una especie de inocencia confesional. En ningún momento pone entre paréntesis su condición de creyente católico; pero va confiando al papel lo que va encontrando en su investigación, sin premeditación defensiva ni apa-

${ }^{17}$ Cf. F. Blázquez, op. cit., pp. 101-104.

18 J. L. L. Aranguren, Catolicismo y protestantismo como formas de existencia, en Obras Completas, vol. 1, Madrid, Trotta, 1994, p. 211. 
sionamiento obnubilante. Estamos ante una obra maestra de filosofia de la religión. Ya lo he dicho: si la óptica hubiese sido teológica, el resultado habría sido bien diferente. No quiero decir que la teología no pueda ser objetiva y justa en sus apreciaciones; pero la experiencia enseña que las aproximaciones teológicas a los temas que aborda Aranguren en este libro adolecen de una cierta servidumbre apologética y confesional. Algo que quedaría bien patente si comparásemos el análisis arangureniano con el llevado a cabo por J. LortL y E. Iserloh, dos de los historiadores católicos - y teólogos - que con más simpatía se han aproximado, algo después que Aranguren, al estudio del protestantismo ${ }^{19}$. Tal vez no haya que insistir más en ello: la filosofía de la religión no es hija de obediencias doctrinales. Sus señas de identidad son la argumentación y la libertad. Puede así, en mayor medida que la teología, relativizar legados confesionales y relajar su obediencia al argumento de autoridad. Es, sin duda, lo que hizo Aranguren. Al escribir esta obra fue heterodoxo antes de proponérselo.

Al pretender ofrecer una reflexión de conjunto sobre el pesamiento religioso de Aranguren, no podemos dar cuenta detallada del contenido de este libro. Baste decir que es un gran relato con voluntad de concordia. Se intenta «heredar» lo mejor de ambas tradiciones, la católica y la protestante. Con finura intelectual, y con brillante estilo literario, se cotejan ambos talantes. La obra se inicia, por cierto, con una teoria del talante que su autor reivindica como aportación original.

Eso sí: Aranguren deja claro que no se es creyente cristiano por talante, sino por la gracia de Dios. Pero, hecha esta importante advertencia teológica, lleva a cabo un lúcido análisis comparativo entre la forma de existencia católica y la protestante ${ }^{20}$. El protestantismo vive el pathos de la distancia. Insiste en la diferencia cualitativa entre Dios y la criatura. Su Dios es lejano, misterioso, trascendente. Las vías de acceso a él son precarias. La razón humana, apostrofada por Lutero como eciega prostituta del demonio», no puede - ni debcprobar su existencia. Sólo queda la fe desnuda y trémula, entendida como confianza. Una fe a la que Lutero prohibió severamente todo apoyo externo. De ahi que restringiese el número de sacramentos y el valor de las mediaciones. El protestante se enfrenta, casi en solitario, a su Dios y a su salvación. Sólo existe un canal privilegiado de comunicación con el creador: la Biblia. Sin instancias magisteriales, el protestante se inclina sobre ella con temor y temblor. No existe en el protestantismo el «pensamiento figurativo» del que hablaba Eugenio D'Ors. La furia iconoclasta protestante no se detuvo ni ante las más preciosas obras de arte. Era más grandioso acceder a Díos en perfecta soledad, sin muletas ni escaleras, sin representaciones sensibles ni subvenciones imaginativas. Dios ha hablado y sólo eso importa. No es extraño que el protes-

${ }^{10}$ Cf. J. Lortz y E. Iserloh, Kleine Refomationsgeschichte, Freiburg-Basel-Wien, Herder, 1969.

J. L. L. Aranguren, Catolicismo y protestantismo como formas de existencia, op. cit. pp. 232 y ss. 
tantismo diese lugar a hombres de una interioridad apasionada, como Kierkegaard. Fue él quien dejó escrito que a Dios tenemos que acercarnos «de uno en unow.

Aranguren ve al creyente protestante abocado «trágicamente a la angustia y la desesperación». El protestantismo es la cuna de la Sorge heideggeriana. En cambio, la forma de existencia católica está presidida "por la serenidad, el equilibrio y la armonia». El talante católico es «bien temperado y esperanzado» ${ }^{21}$. El protestante insiste en que la criatura es "polvo, miseria, nada»; el católico añade que, a pesar de ello, «es imagen de Dios». Es posible rastrear -prosigue el católico- una cierta «analogía» entre Dios y su criatura; analogía que el protestantismo, y en concreto el primer $\mathrm{K}$. Barth, rechazará airadamente.

Piensa Aranguren que el protestantismo conduce al «extremo totalitarismo de Dios» y a la «aniquilación de la criatura» ${ }^{22}$. El catolicismo, en cambio, los pone a trabajar a los dos en buena armonía y estrecha colaboración, en una especie de coincidentia oppositorum. El catolicismo pretende «conciliación de la justicia y el amor divinos, de la causalidad divina y la libertad humana, del pecado y de la gracia, de la heterosoteriología y de la exigencia de cooperación mediante el merecimiento propio. Ponderación, equilibrio, no entweder-oder, sino "lo uno y lo otro"»"

La forma de ser católica es distendida, serena, esperanzada. Ni se vilipendia ni se absolutiza la razón. Aristóteles puede ser - de hecho ha sido- un aliado; no es necesario identificarlo con el demonio, como hacía Lutero. $Y$ las vías de acceso a Dios son plurales y comunitarias. El católico no es, como Lutero, un «solitario Robinsón de la fe» ${ }^{24}$. Se ve así libre del «sacro terror» que embargaba a Lutero. El católico cree en la eficacia de las mediaciones. De ahí que rechazase la amputación sacramental de Lutero. Siguió afirmando que los sacramentos eran siete. Y continuó rezando por sus muertos, convencido de que la salvación posee una dimensión comunitaria.

$\mathrm{Y}$ algo muy crucial en lo que, con gran lucidez, insiste Aranguren: el «antitradicionalismo» de Lutero. No parece exagerado situar en este punto el drama del protestantismo. Lutero quiso empezar de nuevo. En palabras de Aranguren «... decidió echar a un lado la historia entera de la Iglesia para encararse directamente con la Biblia y leerla en la soledad, a su albedrio» ${ }^{25}$. El resultado fue que «Lutero no predicó nunca la Biblia, sino su Biblia, una palabra mutilada, aislada, conformada (...) a la medida de su intemperada disposición anímica» ${ }^{26}$.

Era muy arriesgado pretender refundar el cristianismo cuando éste contaba ya diecisêis siglos de existencia. Lutero se olvidó de la historia, del tiempo

\footnotetext{
${ }^{21}$ Ibid., p. 212.

$=$ Ibid, p. 299.

${ }^{23}$ Ibid., p. 233 .

${ }^{24}$ Ibid., p. 245.

* Ibid

${ }^{26}$ Ibid, p. 246.
} 
transcurrido, de la huella que los días, cuando son muchos, van dejando. El cristianismo había acumulado luces y sombras. Lutero quiso heredar las luces y desentenderse de las sombras. Pronunció su gran maldición sobre el lado sombrío de la Iglesia cristiana. Creyó que podía quedarse con el trigo y quemar la paja. Pero ya el mismo Jesús frenó en seco a los impacientes dejando claro que la cizaña y el trigo crecerán juntos «hasta la sicga». No son posibles clarificaciones intrahistóricas definitivas. Sólo la siega, si llega, arrojará la deseada claridad última.

Con todo - Aranguren lo reconoce-Lutero llevó a buen puerto su empresa. Sólo un genio religioso como él podía salir airoso de la revolución que orquestó. Tuvo la suerte de que el cristianismo da mucho de sí. Y él supo arrancarle tesoros ocultos que otros no habían vislumbrado. Eso sí: también cubrió de penumbra facetas genuinas y esenciales. A Lutero, como a todos, se le mezcló el trigo con la cizaña. $Y$, como acabamos de abogar por la no-separación precipitada de ambas dimensiones, dejaremos para el tiempo de la siega el juicio definitivo sobre el buen o mal hacer de Lutero. Es lo que hace Aranguren. Sin arrogarse función judicial alguna - nada más ajeno al «talante» arangureniano-, heredó del protestantismo su énfasis «existencial» y lo unió a su catolicismo. De ese cruce salió —afirma - «mi propia posición, que cabría caracterizar como un catolicismo existencial ${ }^{27}$.

Decía Ortega que Dilthey «no tuvo tiempo para hacer su obra porque el tiempo que tuvo fue un puro contratiempo» ${ }^{28}$. También el tiempo en el que Aranguren escribió esta obra fue un puro contratiempo. Eran fechas de radical y torpe antiprotestantismo. De hecho, aunque el libro se publicó con censura eclesiástica —el censor fue el P. Ramón Ceñal-, los ambientes eclesiásticos reaccionaron, como ya hemos apuntado, con visceral acritud. El jesuita J. M. Granero, además de apoyar su crítica en argumentos patrióticos, sorprendió a Aranguren con una apelación a lo cuantitativo: como en España los protestantes son pocos y los católicos muchos, la verdad está de parte de los últimos ${ }^{29}$. Y Roig Gironella, también jesuita, acusó a Aranguren de compartir el talante desesperado de los protestantes. Aranguren respondió, entre irónico y dolido, que de lo único que casi desesperaba era de que Roig Gironella llegase a comprenderle ${ }^{30}$. Otro jesuita, A. Arias Prada, escribió enfáticamente: «Señor Aranguren, religión verdadera no hay más que una.» $Y$ concluía, en un alarde de espíritu «ecuménico», que «el protestantismo es billete falso» ${ }^{31}$. Una vez más, la Iglesia llegó tarde.

Muy diferente fue la reacción de los intelectuales seglares. J. M. García Escudero escribió: «Es Aranguren el principal representante de ese grupo de p. 78 .

${ }^{7}$ E. López-Aranguren, J. Muguerza y J. M. Valverde (eds.), Retrato de José Luis L. Aranguren,

* I. Ortega y Gasset, Obras Completas, vol. 7, Madrid, Alianza, 1983, p. 62.

Cf. F. Blázquez, op. cit. p. 102.

औI Ibid., p. 103.

"Ibid., p. 104. 
escritores seglares vocado a los temas religiosos surgidos en la postguerra española, y que está intentando algo muy importante, no ensayado hasta hoy entre nosotros: hablarnos no ya de religión sino de nuestra manera de vivir la religión.» Y para D. Ridruejo «Aranguren está ya con carácter de maestro a la vanguardia de los que comprenden y obran frente a los que, cómodamente, vetan y duermen». Los elogios de Laín Entralgo, que tanto contribuyó a la dedicación universitaria de Aranguren, son tan generosos como quien los escribió: «Nunca, desde Unamuno, ha escrito un seglar español unas páginas tan pcnetradas de religiosidad intelectual y de saber teológico; nunca, desde Balmes, y aun desde más allá, ha buceado un católico hispano tan serena y sutilmente en los senos de la espiritualidad protestante» ${ }^{32}$.

Hay que reconocerlo: Catolicismo y protestantismo como formas de existencia, publicado por primera vez en 1952, ha corrido una suerte extraña. Cuando vio la luz, no había en España muchas luces para comprenderlo, y, cuando se le pudo comprender, se le dejó de leer. Pero esto es secundario. La obra quedará ahí para mostrar que el proverbio árabe «un hombre se parece más a su tiempo que a su padre» - citado a veces por Ortega - no es de obligado cumplimiento. De cuando en cuando, ciertos hombres rompen el cerco de su adversa circunstancia histórica y anticipan lúcidamente el futuro. Es lo que logró Aranguren. La actual hora de entendimiento ecuménico, de diálogo entre catolicismo y protestantismo - ambas confesiones han terminado por fusionar sus teologías en temas cruciales - tiene en el caviloso investigador de Pablo Aranda un precursor insigne.

Es hora de concluir este apartado. Hemos contemplado el primer frente externo en el que se batió Aranguren. Su aproximación al exterior fue lenta y nunca total. Más bicn fue el exterior quien llamó a su puerta. Aranguren nunca se anunció a sí mismo. Fue la sociedad quien demandó su orientación. En su despacho de la calle Fortuny escuché por primera vez la palabra SIDA. Una llamada telefónica del diario El País le requería para que iluminase el tema.

Pero lo nuestro es acompanarle, ahora ya más brevemente, en su acción católica intelectual.

\section{Gredos y otras alturas}

La gran obra teórica que acabamos de evocar no mermó la religiosidad intimista de su autor. Continuó participando en aquella liturgia solemne y esmerada que nos llegaba de las tierras de Guardini, Casel, y la emblemática abadía de María Laach. Inciuso en sus últimos años seguía Aranguren la misa por televisión y la encontraba «muy interesante».

32 Ibid., p. 101. 
Pero el esfuerzo intelectual realizado dio sus frutos. El catolicismo de Aranguren se abrió a nuevos horizontes. Las lecturas de Mauriac, Bernanos, G. Greene, y otros muchos novelistas, poetas y pensadores le ayudaron a comprender lo que él llamó «el espíritu del tiempo». Es verdad que, en temas de moral, continuó durante mucho tiempo aferrado a un extraño rigor. Causa sorpresa la facilidad con la que descubre pecado por todas partes. García Escudero llegó a acusarle de «cierto tenebrismo» ${ }^{33}$. No le faltaba razón. Es Ilamativo el desenfado con el que adjudica el estado de gracia o de pecado a los grandes creadores artísticos ${ }^{34}$.

Pero no es éste nuestro tema. Si aludimos a él es para aventurar una tesis: tenemos la impresión de que, en Aranguren, la apertura religiosa precedió a la apertura moral. Es más: nos parece que la primera fue condición de posibilidad de la segunda. Sólo después de cerciorarse de que el cristianismo es una religión profundamente humanista se abrió Aranguren a una moral más indulgente y misericordiosa. Sólo entonces se resquebrajó su severidad. Algo, por lo demás, nada extraño teniendo en cuenta la centralidad de lo religioso en su vida y en su pensamiento. Su ética y su religión caminaron siempre de la mano.

Catolicismo y protestantismo como formas de existencia marca, pues, un nuevo inicio. Aranguren, como en su día Unamuno, se propone excitar las conciencias, provocar un nuevo despertar religioso. Es lo que intenta en el resto de su obra sobre temas religiosos, especialmente en Catolicismo, día tras día. Él mismo calificó esta obra como una «suerte de diario intelectual, si bien fragmentario, de la vida católica española». El libro reúne artículos publicados entre 1949 y 1953. En su segunda parte reproduce las colaboraciones que, bajo el título También entre los libros anda el Señor, había venido publicando en El Correo Literario, de Barcelona. Aquella publicación quincenal alcanzó un gran eco. En ella - escribe Olegario González de Cardedal - «alertó a los españoles de cuanto ocurría en Europa de valioso, ejemplar y aleccionador, tanto intelectual como religiosamente». González de Cardedal siente profundo agradecimiento a Aranguren porque, a través de aquellos artículos, «me acercó al pensamiento europeo y en sus columnas me encontré con nombres de filósofos y teólogos alemanes a los que luego pude escuchar en las clases, e incluso hacer el doctorado con ellos» ${ }^{35}$.

Aranguren quiere «dotar de eficacia secular, mundana -a saber; intelectual, científica, literaria, artística, política, social-- a la religión cristiana» ${ }^{36}$. Y todo ello como «expresión de amor y adhesión a la Iglesia». Más tarde, cuando

"Citado por J. L. L. Aranguren, Contralectura del catolicismo, en Obras Completas, vol. 1, Madrid, Trotta, 1994, 623.

lbid, pp. 623 y ss.

* O. González de Cardenal, aContra la estrechez intelectual\%, en $A B C$, 18 de abril 1996, p. 55.

3. J. L. L. Aranguren, Calolicismo, día tras día, en Obras Completas, vol. 1, p. 503. 
suene la hora de la heterodoxia, restringirá este amor y adhesión «a la Iglesia eclesial»; a la otra, a la «Iglesia eclesiástica», pasará a considerarla como «un curioso fenómeno digno de estudio» ${ }^{37}$.

Adelantándose a su tiempo, reivindica el papel del laicado. No cree que la religión sea cosa exclusiva de curas. Llega incluso a escribir: «... quién sabe si, como algunos desean, se restablecerá algún día el "diaconado" como vocación subsistente y propias ${ }^{38}$. Se considera a sí mismo como una especie de apóstol laico que anuncia «orgullosamente la sabiduría perenne del catolicismo». Desea hacerlo «interesante» a todos, especialmente a los jóvenes.

A pesar de su estricta ortodoxia -e incluso conservadurismo-, el libro volvió a ser blanco de las iras eclesiásticas y recibió un monitum del arzobispado de Madrid. Más tarde, en la «Introducción» a Obras selectas, escribió Aranguren: "Sería yo quien "censurase" el libro, haciéndolo más "avanzado" de lo que es.» Y en su valiente Contralectura del catolicismo, en 1978, reconoce las «limitaciones» de su obra de entonces. Pero la Iglesia no era ya la misma. El concilio Vaticano II, en el que Aranguren tantas esperanzas depositó -llegó a calificarlo como el «acontecimiento más importante del siglo $\mathrm{xx}$ »-, había suscitado grandes expectativas. Aranguren las compartió, pero la rápida involución posterior se encargó sobradamente de rebajar su entusiasmo.

Y tampoco Aranguren era el mismo. «Mi lector actual -escribe en Contralectura del catolicismo- sabe que, salvo "metafísicamente", no creo ser el mismo de entonces. ¿Sigo representando lo mismo que entonces? Por encima o por debajo de todas las diferencias, creo que sí» ${ }^{39}$.

Y lo que Aranguren representó siempre - con las diferencias que él admite- fue un cristianismo culto y abierto. Estaba convencido de que, aunque la religión no es «sólo cultura», es «también» cultura. Consideraba, incluso, que la religión es «el núcleo central de la filosofia y, en general, de la cultura toda ${ }^{40}$. De ahí que librase su particular batalla contra el oscurantismo, la ignorancia y la intolerancia de la Iglesia española de su época. Su enorme caudal de lecturas le mantenía al cabo de la calle de lo que ocurría en Alemania, Francia, Inglaterra y otros países. Observaba que esas Iglesias aunaban pensamiento y creencia. Y, como una especie de Quijotc, se propuso ayudar a que, también en España, la fe y la cultura caminasen juntas. A pesar de que su religiosidad fue sencilla y confiada, nunca propugnó la fe del carbonero. Quería una fe lúcida e informada. Con frecuencia manifiesta su temor de que una Iglesia ignorante y férreamente dogmática ahuyente a los que piensan y trabajan en el campo de la cultura.

Acabamos de mencionar la religiosidad sencilla y confiada de Aranguren. Es la que, durante años, se cultivaba en las Conversaciones Católicas de Gredos.

"7. L. L. Aranguren, Contralectura del catolicismo, op. cit. p. 539.

38 J. L. L. Aranguren, Catolicismo, dia tras dia, op. cit., p. 417.

39 J. L. L. Aranguren, Contralectura del catolicismo, op. cit., p. 540.

4. J. L. L. Aranguren, Catolicismo y protestantismo como fomas de existencia, op. cit, p. 230. 
Y Aranguren, junto con don Alfonso Querejazu, fue su principal promotor. La inspiración le vino de las Conversaciones Católicas Internacionales de San Sebastiấn, a las que asistió durante varios años.

Gredos, o lo que se dio en llamar el «espíritu de Gredos», se convirtió en una experiencia crucial para Aranguren y para los intelectuales católicos de su época. A Gredos se acudía a "meditar, conversar y orar juntos». La religiosidad allí cultivada cra ingenua e intimista. Los asistentes se dejaban envolver por la música y la liturgia que, con tanto esmero, cuidaban los seminaristas de Ávila. Aranguren dice que, durante los días de las Conversaciones, vivían en «retiro» y «comunidad»" 4 . Era un escenario único para la reflexión y la piedad. Una especic de ejercicios espirituales para intelectuales.

Aranguren evoca el espíritu orsiano que presidía la liturgia de Gredos. Se cuidaba todo: los gestos, las posturas, la pronunciación, el canto gregoriano. Todo iba orientado a crear un clima que favoreciese la elevación cspiritual. Se trataba de la «fe vivida» y compartida. El diálogo era fundamental. Aranguren recuerda que las comunicaciones eran «pretextos» para abrir cauce a la conversación, al intercambio de ideas y cxpcriencias. Sc trataba de conocer y comprenderse, de testimoniar —en palabras de Aranguren- «la unidad en la libertad».

Muchos años después, Pedro Laín, uno de los fieles a Gredos, evoca el intimismo religioso-burgués de aquellas reuniones. Reconoce que faltó el diálogo con el ateísmo y el agnosticismo. Y tampoco se hicieron eco de la miseria y la injusticia que asolaha nuestro país. De ahí que carecieran «de verdadero arraigo en la verdadera realidad de este mundo». Lain concluye: «Acaso les sobrase, por otra parte, distinción, finura, elitismo, como ahora es tópico decir» ${ }^{42}$.

A pesar de su carácter eminentemente conscrvador, las Conversaciones Católicas de Gredos despertaron las suspicacias de la jerarquía eclesiástica. El P. Ceñal, figura clave de Gredos, fue enviado por los jesuitas a Chile. Aranguren le dedicó una emotiva despedida. $Y$ es que, aunque muy tímidamente, en aquellas Conversacioncs se escucharon reproches y críticas a la jerarquía.

Y en esos reproches y críticas estaba Aranguren cuando, en 1961, escribió una carta a don Alfonso Querejazu comunicándole su decisión irrevocable de abandonar las Conversaciones de Gredos. Era su adiós a la religiosidad esteticista e individualista de aquellas alturas. Y era el comicnzo de otras inquietudes: «La hora del catolicismo au-dessus de la melée, la hora de la fe "trascendente", planeando por encima de los problemas políticos, sociales, económicos, había pasado yàn ${ }^{43}$.

En Gredos continuó aleteando una forma de catolicismo que ya no era la que exigían los nuevos tiempos. Aranguren decidió distanciarse, serle «infiel».

4) Para una detallada información sobre las Conversaciones Católicas do Gredos remitimus a F. Blázquez, op. cit., pp. 115-126.

42 P. Iaín Entralgo, Descargo de concioncia (1930-1960), Barcelona, Barral, 1976, p. 432.

${ }^{4}$ J. L. L. Aranguren, Mentorias y esperanzas españolas, pp. 77 y 5 . 
Y terminó dándose de baja de lo que denominó «aquel místico Country Club». Pero semejante «espantada" no le impidió escribir: «Creo que, para quienes pertenecíamos al "círculo de Gredos", fue una experiencia importante de catolicismo vivido-representado..., en él nos va $\rightarrow$ y se nos fue- una parte de nuestro pasado, que no puede volver» ${ }^{4}$.

Previamente, en 1953, Aranguren había practicado otro abandono: el de la religiosidad que vivió en el colegio de los jesuitas. Lo rememora, con envidiable calidad literaria, en el artículo «Nuestra Señora del Recuerdo». Es la historia de una despedida. Fue su última visita al colegio. Después de la misa recorrió por última vez aquellos espacios familiares. De pronto, en el salón de actos, se encontró con los miembros de la Asociación de Antiguos Alumnos. Estaban reunidos «devanando el pasado, estirándolo, galvanizándolo. Eran más fieles que yo». Aranguren comprendió que nada tenía que hacer en aquella reunión. Pasó de largo y salió del colegio. «El pasado - escribe-quedaba encerrado en aquellos muros. Mi reloj continúa inquieto adelante. Hasta que se le rompa el muelle real, hasta que se le salte la cuerda» ${ }^{45}$.

Por suerte para todos, el reloj era fuerte y pasaron muchos años antes de que, un 17 de abril de 1996, se le saltase la cuerda para siempre. Ese día murió un trozo de la historia intelectual de nuestro país y de la historia del catolicismo cspañol. En el tanatorio y en el pequeño cementerio de Ávila se dieron cita familiares, amigos, discípulos y exponentes de la cultura y la política. Faltaron, incomprensiblemente, los representantes de lo que Aranguren llamaba «la Iglesia eclesiástica». Uno hubiera esperado que algún exponente de esa Iglesia se acercara a agradecer al maestro fallecido los servicios prestados. Servicios que, como hemos visto, no fueron nada insignificantes. Pero, por lo visto, prevalecieron otros intereses, tal vez viejos rencores. Lo constato sin ira, sólo con tristeza. Y paso a preguntarme si la "heterodoxia» de Aranguren fue tan demoledora como para justificar que la jerarquía eclesiástica no encontrase el camino que conducía a su féretro.

\section{Cristiano heterodoxo}

La heterodoxia no es un dato tardio en la vida de Aranguren. Hemos visto que ya la publicación de Catolicismo y protestantismo como formas de existencia (1952) suscitó los recelos de los guardianes de la fe. El mismo destino corrió Catolicismo, día tras día, en 1955. Y, de forma muy especial, La ética de Ortega, en 1958. Es éste un escrito especialmente revelador del talante de Aranguren. Siempre atento a las causas en peligro, salió en defensa de su maestro. El P. Santiago Ramírez, dominico, había abandonado por un momento su devota dedicación a la filosofía escolástica para, por supuesto desde ella, lanzarse

* Ibid., pp. 271 y s.

4s Ibid., pp. 30 y ss. 
a la caza de los errores y heterodoxias de Ortega. Aranguren - junto con Laín Entralgo y Julián Marías- llegó a temer que Ortega corriese la misma suerte que Unamuno y diese con sus huesos en el Indice de libros prohibidos. Invitaba, por ello, al P. Ramírez a «entender» antes de «condenar». Sin tratar de canonizar la ética de Ortega, muestra su posible apertura a la religión y protesta de que «en nombre del cristianismo» se le intente condenar.

Aranguren fue, pues, percibido, casi desde que comenzó a escribir, como heterodoxo. La jerarquía católica no veía con buenos ojos que un seglar invadiese el campo de la teología, reservado por entonces al clero. Pero no es a este género de heterodoxia al que nos referiremos en este apartado. Nuestra atención se centrará en el Aranguren que se autopercibe como heterodoxo. Fue la vida misma la que le condujo a la heterodoxia y la disidencia. Su contacto con la juventud universitaria, la expulsión de la cátedra y su prolongada permanencia en California ensancharon su horizonte intelectual y religioso. Fuc así como penetró en su vocabulario, teórica y prácticamente, el término «heterodoxia». Y fue así como su catolicismo esteticista e intimista se fue transformando en un cristianismo abierto y crítico.

Algó que quedó patente en su libro La crisis del catolicismo (1969). Es un libro valiente en el que aboga por una Iglesia abierta, profética y socialmente comprometida; una Iglesia que no piense sólo en enseñar, sino que se muestre dispuesta a aprender; que revise sus anquilosadas estructuras y su artificioso e ininteligible lenguaje eclesiástico; que pierda el miedo a lo nuevo y abra en su interior generosos espacios a los grupos de cristianos inquietos que andan a la búsqueda de nuevas formas de expresión litúrgica y doctrinal. Confiesa que ecuesta trabajo percibir el soplo religioso" en medio de tanta burocracia eclesiástica.

Es más: en Memorias y esperanzas españolas (1969) concibe diferentes grados de adhesión al catolicismo, «situaciones intermedias» o de «liminaridad», pertenencias difusas y participaciones parciales. Algo sin duda muy alejado del rigor con el que, en épocas anteriores, juzgaba estos temas.

Y ya en fechas más cercanas, en Sobre imagen, identidad y heterodoxia (1982), escribe: «Ni decididamente "dentro", ni decididamente "fuera", ni con la jerarquía, ni, pese a todo, contra ella; heterodoxos sí, pero parece que ya no herejes -categoría en trance de supresión-y, desde luego, no cismáticos» ${ }^{46}$. Es consciente de que no es posible «poner puertas a la fe» ni saber quién está dentro o fuera. La ortodoxia se le va haciendo cada vez más difícil. Pero, al mismo tiempo, cree que las espantadas, los abandonos de la Iglesia conducen a la esterilidad, a la marginalidad, a «evanescerse» en una especie de gnosis "minoritaria, solipsista, espiritualista». Prefiere quedarse y resistir: «Ya es verdad, y lo será cada vez más, que es católico, que es cristiano quien, desde el fondo

4 J. L. L. Aranguren, Sobre imagen, identidad y heterodoxia, en Obras Completas, vol. 3, Madrid, Trotta, 1995, p. 401. 
de su propia contradicción, dice que lo es, siempre según su manera personal, no vaciada de la propia heterodoxias ${ }^{4}$. Y aconseja a la Iglesia que no se parta el pecho por la ortodoxia. Ésta es algo cambiante e histórico. Pone el ejemplo de Santo Tomás: su doctrina pasó de ser condenada a convertirse en «filosofia oficial de la Iglesia». Por lo demás - Aranguren insiste en ello-, la heterodoxia de hoy será la ortodoxia de mañana.

Más que heterodoxo en la acepción fuerte del término, Aranguren parece un rcformador moderado - «ni con la jerarquía, ni, pese a todo, contra ella»-un cristiano crítico, atcnto a los signos de los tiempos. Pero, probablemente, es lo que él entendía por heterodoxia.

Tal vez se podría afirmar que su heterodoxia se centró preferentemente en el campo de la eclesiología. Sin estridencias, pero con firmeza, denunció los arreglos entre la Iglesia y el poder. Blanco preferido de su crítica fue también la burocracia eclesiástica. La cncontraba anquilosada, miope, carente de atractivo. Consideraba difícil que, a través de ella, se pudiese filtrar el impulso evangélico.

Pero es posible que la más lograda expresión de su heterodoxia esté en el tránsito del catolicismo al cristianismo. Por eso la hemos clegido como título de estas páginas. Ya indicamos que no se trató de un cambio dramático ni espectacular. Ni siquiera hubo, a nuestro entender, un abandono total del catolicismo. Se trató, más bien, de un significativo desplazamiento de acentos. Veámoslo.

En el prólogo a Contralectura del catolicismo confiesa que la palabra «catolicismo" ha terminado por no gustarle. Le suena - dice- a lo que «por desgracia» tantas veces ha sido: «catolicismo frente a cristianismo». En consecuencia, lo que en otros tiempos llamó Catolicismo, día tras dia lo llamaría hoy Cristianismo, día tras día. Pero, como tal título podría tener resonancias muy «piadosas», preferiría sustituirlo por la de Cristiano, pese a todo o Cristiano heterodoxo ${ }^{48}$.

En su rechazo del término «católico» influyen, además, sus connotaciones de «nacionalcatolicismo». Aranguren no puede olvidar el extraño matrimonio entre el régimen franquista y la «Iglesia eclesiástica».

Por último: lo católico - escribe- «es una palabra que subraya unilateralmente lo "universal", uniforme, general y deja en la sombra lo singular, pluriforme, particular de cada modo de ser cristiano" ${ }^{49}$.

Aunque, en estricta teoría, no hay motivos para establecer tan tajante contraposición, cn la práctica hay que dar la razón a Aranguren: con demasiada frecuencia, lo católico ha sofocado, en beneficio de una abstracta universalidad, lo individual y pluriforme.

Ibid., p. 409.

48 J. L. L. Aranguren, Contralectura del catolicismo, op. cit., p. 537.

+\% J. L. L. Aranguren, Sobre imagen, identidad y heterodoxia, op. cit., p. 409. 
La preferencia por lo cristiano frente a lo católico tuvo consecuencias en la vida de Aranguren. Supuso una lenta decantación por lo esencial, un progresivo anclaje en una religiosidad sobria y muy personalizada. Hemos visto someramente cómo en su - digamos- «época de católico» estaba en todos los frentes donde se dilucidaban asuntos religiosos. Su acción católica intelectual le conducía a ir de incendio en incendio, siempre con voluntad de "salvar" las esencias de lo católico. Es muy posible que, en su generación, ningún otro pensador laico arrimase tanto el hombro para vivir, explicar y defender su catolicismo. Catolicismo, día tras día es tal vez la expresión más lograda de esta especie de propósito misionero. Los escritos que integran esta obra tienen una clara divisa: el catolicismo no debe quedar al margen de cuanto se mueve en el ámbito de la cultura. Se percibe un manifiesto deseo de arrimar el catolicismo español al catolicismo europeo. Aranguren se dio cuenta de que la Iglesia española era una Iglesia sin teólogos. Había, por supuesto, profesores de teología; pero andaban muy ocupados en completar su catálogo de «adversarios»; algunos exhibían triunfalmente a comienzo de curso, como preciado trofeo, los nuevos advesarios de sus tesis que habían cazado durante la sesuda investigación veraniega. Aranguren, en cambio, informaba a sus lectores del acaecer teológico de otras latitudes. Muchos se enteraron, gracias a sus artículos, de que, fuera de nuestras fronteras, las aguas bajaban revueltas y se comenzaba a hablar de secularización, e incluso de secularismo. En definitiva, durante su «época católica», Aranguren pensó y ejerció la función del intelectual católico. Estaba convencido de que, abordados por un laico, los temas religiosos se vuelven más apasionantes y atractivos. Pensaba que, cuando el clérigo aborda los mismos asuntos, se sabe de antemano lo que va a decir. El tema pierde así mordiente.

En cambio, durante su «época cristiana», que, curiosamente, coincide con una mayor dedicación a los temas éticos y sociopolíticos, Aranguren deja de echarle horas extraordinarias al tema religioso. Sólo esporádicamente volverá sobre los asuntos de antaño. Únicamente quedará un compromiso fijo: el Foro sobre el Hecho Religioso. Nunca faltó a esta cita. Y siempre dio cuenta de sus resultados en la prensa. Quién sabe si lo vería como la prolongación «cristiana" de las "católicas" Conversaciones de Gredos...

Sería un error pensar que, durante esta larga época, Aranguren se despojó de su dimensión religiosa. Los que le tratábamos y algunas veces - pocaslográbamos traspasar la barrera de su, en tales temas, natural pudor, sabemos que no fue así. Hubo, únicamente, una opción por la sobriedad y el retraimiento. Tal vez pensó que su voz ya no era tan necesaria, que en el páramo teológico de antaño habian surgido nuevas palabras, renovados e innovadores proyectos teológicos. Sin olvidar, naturalmente, la «desmoralización» -una palabra muy suya - que le produjo la torpe involución que siguió a las expectativas levantadas por el concilio Vaticano II. Tal vez se convenció de que lo católico, a lo que él tantas energías había dedicado, tenía poco remedio. $O$, quizás, los nuevos 
quehaceres no dejaban espacio para más. Lo cierto es que el Aranguren cristiano heterodoxo encontró una forma muy brillante - $y$ muy suya - de manifestar su heterodoxia: el silencio. Con él obsequió a la «Iglesia eclesiástica» a la que, en otros tiempos, tantos servicios había prestado. Una salida, como todas las suyas, repleta de dignidad.

Por último: Aranguren insistía en que lo suyo era la heterodoxia, no la herejía ni el cisma. Y se trató de una heterodoxia que afectaba fundamentalmente a la praxis del catolicismo que le tocó vivir. $\mathrm{Y}$ a algunos contenidos accidentales y cambiantes. Pero no parece que el nervio de su universo religioso sufriese sacudidas dramáticas. No se debate con los grandes temas de la teología fundamental o de la filosofía de la religión. Sólo muy esporádicamente alude, por ejemplo, a la dificultad de compaginar la fe en un Dios bueno y omnipotente con el enigma del mal en el mundo. Lo hace, eso sí, gráficamente. Pone el ejemplo de un tranvía que descarrila. Mueren obreros y madres de familia que dejan huérfanos a sus hijos; se salvan, en cambio, «los malvados». «Con la razón humana», advierte, no puede «comprenderse» la Providencia. Y concluye: «Los ires y venires de Dios son misteriosos» ${ }^{50}$.

Pero Aranguren fue un hombre bien dotado para el misterio. Tres años antes de su muerte, en diálogo con Javier Mugucrza, afirmaba estar «al cabo de la calle» de que «para muchísima gente» la muerte de Dios es una «realidad irreversible». Y añadía: «... pero para mí personalmente, en tanto que creyente, Dios no ha muerto o, si usted quiere, creo no haber perdido totalmente la sensibilidad para el "misterio", y hay capítulos de la ética que no sabría cómo abordar si, de algún modo, no lo hago "desde la religión" "s1. Uno de ellos es el de la solidaridad. La considera «heredera de la fraternidad cristiana» y no cree que pueda, como la justicia, descansar únicamente en un tratamiento contractual. Remite a la religión.

No pretendo insinuar que su fe estuvo siempre a salvo y que no conoció la experiencia de la noche oscura. Creo, con Pedro Cerezo, que experimentó la desolación y la crisis de fe. Pero apenas la confió al papel. Es necesario intuirla, leerla entre líneas. Con todo, estoy convencido de que, sin ella, difícilmente hubiera podido recrear las dramáticas búsquedas religiosas de Lutero, Pascal, Kierkegaard o Unamuno. Cuando alguien relata esas tensiones «de oídas», sin haberlas conocido de cerca, no alcanzará nunca la fuerza literaria y emocional que posee la narración de Aranguren en Catolicismo y protestantismo como formas de existencia.

Tenemos que ir pensando en concluir este recorrido por cl pensamiento religioso del maestro y del amigo. Y lo haremos en estricta continuidad con el párrafo anterior. Es decir: volveremos sobre la experiencia de la noche oscura. Es bien sabido que esa experiencia tiende a crecerse en los momentos

${ }_{50}$ J. L. L. Aranguren, Catolicismo, día tras dia, op. cit, p. 439.

${ }^{51}$ E. Lopez-Aranguren, J. Muguerza y J. M. Valverde (eds.), Retrato de José Luis L. Aranguren, p. 87 . 
finales, en los años y los días que preceden al ocaso definitivo. Por suerte poseemos alguna información sobre cómo encaraba Aranguren su adiós a todo lo que había defendido y amado en esta tierra. Será nuestro último, ya breve, apartado.

\section{Y, al final, los puntos suspensivos...}

Al final de la ya mencionada entrevista con Javier Muguerza - la mejor de cuantas Aranguren concedió-, el discípulo pregunta al maestro cómo se siente en cuanto «texto vivo». Aranguren acepta la fórmula que él mismo había empleado en Moral de la vida cotidiana, personal y religiosa (1987). Todos y cada uno de nosotros somos «textos vivos» a la búsqueda de una última comprensión. $Y$, meditativo, Aranguren se pregunta: «iA quién pedir esa última comprensión que consista no tanto en juzgarnos cuanto en decirnos quiénes somos, quién soy?" Vale la pena transcribir íntegramente su respuesta: «No sé, tal vez a la Deidad ante la cual hayamos existido, siquiera como sueño, de suerte que, si "la vida es sueño", sea, haya sido, esté siendo, vaya a ser sueño "de" Díos. Pero ya digo que no sé.»

Era el momento propicio para preguntar tímidamente al maestro si su respuesta implicaría que existe «otra» vida además de «ésta». Muguerza aprovechó la ocasión. Y he aquí la respuesta: «Repito que no sé. Si me tienta pensar en ello es, más que nada, por la posibilidad de seguirla compartiendo con los seres queridos. Pero habría que dejarlo, me parece, en puntos suspensivos» ${ }^{52}$. Y, de mutuo acuerdo, ambos lo dejaron en puntos suspensivos...

El relato posee, al menos para mí, algo de estremecedor. Es la última estación, titubeante y dubitativa, de un itinerario religioso que había comenzado bien arropado por la seguridad y la firmeza en las convicciones religiosas. Entre Ávila y Ávila, entre el comienzo y el final, fueron surgiendo dudas, quebrantos, oscuridades, soledad, preguntas, noches oscuras, muertes que dejan huella. Peldaños, en definitiva, hacia los puntos suspensivos...

Hombre profundo, siempre inclinado sobre el misterio del mundo y del ser humano, Aranguren no abarató la «otra» vida. La dejó en su sitio, allí donde recobra toda su dignidad, en los puntos suspensivos. La «otra» vida no se acopla con evidencia alguna. Su nombre es «esperanza». La llaman así incluso los «ortodoxos»; cuanto más el inquieto «heterodoxo» que fue Aranguren...

Pero hay más. Aranguren no estaba obsesionado por la otra vida. Confesaba que, en este punto, su forma de cntender la religión era «sumamente antiunamuniana». Le parecía que la religión de Unamuno giraba «en torno de sí mismo y de la permanencia de su conciencia y de su personalidad». Él, en cambio, pensaba que, aunque no exista otra vida después de la muerte,

${ }^{\text {s2 }}$ Ibid., p. 88. 
«esto para mí no es forzosamente una respuesta negativa o una abolición de la concepción religiosa, porque la vida eterna puede darse en el instante. Es decir, hay una fusión de eternidad y temporalidad. La eternidad puede incidir en cada instante de nuestra vida. Es una experiencia, en definitiva, mística, si se quiere, pero por lo mismo también poética. Yo no creo que la religión se lo juegue todo o tenga que jugárselo todo a la carta de la existencia de la vida eternas ${ }^{53}$. Y a continuación alude al budismo y a otras religiones orientales que, aunque «no creen en la persistencia de la personalidad individual después de la muerte (...), no dejan de ser manifestaciones religiosas».

Es, de nuevo, la sobriedad de Aranguren, en este tema más próximo a Sócrates que a Unamuno. Si, tras los puntos suspensivos, hace su aparición la nada, el silencio de los silencios, la religión no habrá perdido todas las batallas. La vida eterna puede irrumpir «en cada instante de nuestra vida». No tiene que empezar, necesariamente, cuando caiga el telón. Puede haberse anticipado, haber formado parte de esta vida.

Obsérvese que Aranguren se refiere a la religión en general, sin hacer mención expresa en este contexto del cristianismo. Pero, sin duda, también éste queda afectado, ya que Aranguren habla desde su condición de cristiano.

Conviene advertir que Aranguren no está solo en esta especie de generosa renuncia a un posible más allá. Algunos teólogos protestantes actualcs, a los que él probablemente ya no leyó, practican la misma sobriedad. Incluso grandes místicos, los preferidos de Aranguren, aseguraban que, aunque no hubiera «cielo», su amor a Dios no se resentiría.

También en este tema la actitud de Aranguren respira, pues, grandeza. Hablo de «actitud» porque creo que sólo de eso se trató. Êl no pretendió, en la última cita que he aportado, dilucidar teológicamente si la fe en un más allá es accidental o esencial al cristianismo. Sólo nos dejó dicho que su apasionante aventura religiosa no habría sido «en vano» aunque el cementerio de Ávila tuviese la última palabra. Cosa que, por lo demás, nunca sabremos.

Tiene razón Pedro Cerezo cuando habla del «alargamiento de la ética en la escatología». Si yo tuviera que encerrar en una fórmula la actitud del último Aranguren frente a la escatología, eligiría ésta: «duda, sin desgarro». No hay desgarro unamuniano. Sí hay, en cambio, duda, pregunta. Y si, como formuló Heidegger, "la pregunta es la piedad del pensamiento", el último Aranguren no abandonó la orilla de la piedad. Una piedad hondamente humana, religiosa y filosófica. Piedad, por tanto, al comienzo de su aventura religiosa y piedad al final de ella. Pero con las diferencias que la vida se encarga siempre de introducir, y que nosotros hemos intentado torpemente evocar.

Llegamos, así, al final de nuestra reflexión sobre el itinerario religioso de Aranguren. Salta a la vista que hemos escrito desde la cercanía, desde la empatía. Es posible que ello reste «objetividad» a estas páginas. Pero, también, pudiera

* Es la respuesta a una pregunta de Baltasar Porcel en una entrevista publicada en Destino (9 y 16 de septiembre de 1976). Tomo el texto de F. Blázquez, op. cit, pp. 262 y s. 
darse que sólo la proximidad afectiva haga posible esa mínima objetividad a la que podemos aspirar en nuestras reconstrucciones históricas. En todo caso, hemos hecho lo único que estaba a nuestro alcance: evocar al maestro y al ser querido que, con su vida y su obra, nos enseñó lo único que, en las religiones y fuera de ellas, con vida eterna o sin ella, importa: la bondad. 